\title{
Prediction of Rain Attenuation and Impact of Rain in Wave Propagation at Microwave Frequency for Tropical Region (Uttarakhand, India)
}

\author{
Mukesh Chandra Kestwal, ${ }^{1}$ Sumit Joshi, ${ }^{2}$ and Lalit Singh Garia ${ }^{1}$ \\ ${ }^{1}$ Department of ECE, BTKIT, Dwarahat, Uttarakhand 263653, India \\ ${ }^{2}$ Department of ECE, GRD IMT, Dehradun, Uttarakhand 248001, India \\ Correspondence should be addressed to Mukesh Chandra Kestwal; mukesh.rt20@gmail.com
}

Received 30 January 2014; Revised 3 April 2014; Accepted 24 April 2014; Published 11 June 2014

Academic Editor: Nuno Borges Carvalho

Copyright (C) 2014 Mukesh Chandra Kestwal et al. This is an open access article distributed under the Creative Commons Attribution License, which permits unrestricted use, distribution, and reproduction in any medium, provided the original work is properly cited.

\begin{abstract}
The most classical approach of determining rain attenuation for radio-wave frequency has been to theoretically determine the specific attenuation. At frequency over $10 \mathrm{GHz}$, rain and precipitation can influence the attenuation a lot; the effect of atmospheric attenuation between the source and destination over wireless communication is of major concern and a proper site visit and proper method are required to control the attenuation level so that the performance can be increased. In this paper exponential model has been used to determine the attenuation level for k-region (India) which can be used for region having similar condition. The analyzed predicted attenuation data have been compared with ITU-R measured rain attenuation, and the results will provide useful estimation of rainfall attenuation on microwave links in tropical regions that have similar conditions as (Almora) Uttarakhand region.
\end{abstract}

\section{Introduction}

Rain causes attenuation in electromagnetic waves through the process absorption and scattering [1]; rainfall attenuation is a phenomenon relative to the rainfall rate and frequency which results in increasing path loss, limiting the coverage area, and consequently degrading the system performance. Rain attenuation model in this paper is modeled from data collected over location from different sources. The effect of absorption is presented at certain frequencies, which can be significant at frequencies near $22 \mathrm{GHz}$ and $60 \mathrm{GHz}$ due to water vapor and oxygen, respectively [2-4]. ITU-R is an organization which standardized the rule for telecommunication and provided a step by step approach for prediction of rain attenuation on any terrestrial radio link; however, this model does not perform well in tropical region [5] and at high rainfall rate since average radius of raindrop in tropical region is greater than that in nontropical and data for ITU model is based on data collected from temperate region of the world [6].
Almora is situated in Uttarakhand region with coordinates at $29.62^{\circ} \mathrm{N}$ and $79.67^{\circ} \mathrm{E}$. It has an average elevation of 1,651 meters (5,417 feet). It is located on a ridge at the southern edge of the Kumaon Hills of the Himalaya range which is surrounded by thick forest of pine and fir trees with average annual temperature of -3 to $28^{\circ} \mathrm{C}$, average summer temperature of 12 to $28^{\circ} \mathrm{C}$, humidity of $27 \%$, and $1010 \mathrm{hPa}$ pressure.

The aim of this paper, therefore, is to emphasize on difference between measured rain attenuation in tropical Almora, Uttarakhand, India, and ITU-R predictions and results may also be extrapolated for use in tropical regions that have similar situation as the Uttarakhand; also, the study will be helpful for understanding the rain attenuation characteristics over the Indian tropical region.

\section{Impact of Rain in Wave Propagation}

Before planning wireless network for communication, it is necessary to determine the path loss and broadcast signal 
coverage for the location. The demand for increased data rates and greater bandwidths has required systems to use radio frequencies in the microwave and millimetric wave bands.

Fog attenuation dominates in infrared and optical bands whereas rain attenuation plays havoc at millimetric wave bands. The microwave propagation is affected by changes in lower atmosphere; presence of hydrometeors such as rain, fog, water vapor, and oxygen in radio wave path can produce an extremely significant effect in energy absorption. With increase in rain rate, attenuation in radio link communication is increased, which shows adverse effect at microwave and millimetric frequencies, since EM waves are most effected by scattering $[6,8,9]$ and absorption phenomena. Rayleigh [10] and Mie scattering are the main cause of attenuation at higher altitude of the atmosphere. In the designing of a microwave link, there are several points to be considered like system reliability, economical designs, present and future frequency selection, site planning, and multilevel systems.

With respect to these hydrometeors, the path loss due to rain attenuation has been recognized as major obstacles in design of microwave communication link operating at frequencies above $10 \mathrm{GHz}$ [11]. In (Uttarakhand) India, where excessive rainfall is a common phenomenon throughout the year and rainfall rate varies very much in small location over a small distance, rain attenuation is more significant in causing propagation loss and can cause much havoc for millimetric and microwave signals. Rain attenuation degrades the system performance and limits the usage of higher frequencies for terrestrial LOS communication system. As mentioned earlier, the path attenuation due to rain plays a significant role at frequencies higher than $10 \mathrm{GHz}$, considering all these factors; it is obvious that the attenuation due to rain is required [12].

\section{Rain Attenuation Prediction Models}

Two methods for prediction of rain attenuation on radio wave path have been grouped into two categories: physical method and empirical method.

3.1. Physical Methods. Physical methods are referred to theoretical models (analytical models) which make attempts to reproduce physical behavior involved in the attenuation process. When physical approach is used not all the input parameters are required for analysis, while analytical models offer an insight into the physical processes involved in radio wave propagation through atmosphere; however they invariably require the use of numerical analysis methods to provide solutions to intractable mathematical formulations [13]. A physical method to calculate attenuation is used by practical implementation of labs, and a complete set up is needed before starting the experiments. It is quite hard to establish set-up, and this kind of experiments costs a lot. Most of the time, these models took a lot of time to give the precise results. These are more reliable because the results which we achieved out of the experiments are real problems based and these kinds of experiments required very high experienced person to perform them.
3.2. Empirical Method. Empirical model is based on measurement database stations in different climatic zones within a given zone. The main advantages of these models lie in the simplicity of the mathematical expressions describing them, leading to their straightforward applications like Seville, Paulsen, Seville, Excell model, Cranes two-component model [14], two-component modified exponential model, fitted ITU-R model, Stephens and its derivatives, and specific attenuation model (SAM) by Stutzman and Dishmna among others, to give best fits to measured data, which can be found in literature and comprehensive information on these models can be obtained from COST [15]. Although they do not consider the physical processes underlying propagation in vegetation, they are based on knowledge of the qualitative behavior of absorption and scatter in homogeneous scattering media. These models are relatively new and have been formulated using measured data mostly obtained recently. They have however many drawbacks, not least of which are their strict dependence on specific measured data and their failure to relate to physical process involved.

3.3. Rain Attenuation Model. In the past history there are many attenuation models which can be found in the literature, many of which are revised version and still there are many to go; some of them are ITU rain model, DAH, Lognormal, Assis, Flavin, Crane, SAM, Moupfouma, Yameda, Lin, and so forth [15].

The ITU radio (ITU-R) communication sector is one of the three divisions of international telecommunication union (ITU) which is responsible for radio communication and manages the international radio-spectrum and satellite orbit resources and also enhances standards for radio communication system with the objective of ensuring the effective use of spectrum. Based on data pooled from the United States, CCIR or ITU-R gives an estimate of cumulative distribution of rainfall rate for the entire globe by dividing into five zones. These climate regions represent rain climates typical of those found within in the United States but do not adequately represent the much more intense rain rate region found in the wet tropical regions of Africa, South America, Indonesia, India, or the much less intense region found in the Arctic [16].

(a) Calculation of Excess Path Attenuation. Long term statistics of rain attenuation is evaluated for the location by using ITU-R coefficients and method which can be directly downloaded from ITU-R; reference section can be used to access those data $[7,17]$. Measurement of data is collected from different weather data collection center. An empirical procedure based on the approximate relation between specific attenuation $(A)$ and rain rate is used to find the impact of rain on radio wave propagation:

$$
A(\mathrm{db} / \mathrm{km})=a R^{b}
$$

where $R$ is the rain rate in $\mathrm{mm} / \mathrm{hr}$ exceeded for $0.01 \%$ of an average year which can be obtained from different weather data monitoring center or from metrological data. Parameters $a$ and $b$ are function of polarization and frequency and can be 
obtained from experimental results or simply can be accessed from ITU-R [7].

(b) Converting Rainfall into Rain Rate. In prediction of atmospheric attenuation or rain attenuation, rainfall rate plays a significant role. Since most of the data from weather data collection center is available in millimeter $(\mathrm{mm}$.) and rain attenuation is related to rain rate in $\mathrm{mm} / \mathrm{hr}$ rather than rainfall intensity in $(\mathrm{mm})$, it is necessary to first convert the available rainfall data into rainfall rate while converting rainfall data into exceeded rain rate expression required is as follows.

Divide the given data by observation time $(10 \mathrm{~min}$, 20 min , ..., etc.)

$$
R_{D}=L * \frac{60}{T}
$$

where $R_{D}$ is the rain rate in $\mathrm{mm} / \mathrm{hr}$ and $L$ is the maximum rainfall in $\mathrm{mm}$ for time interval $T \mathrm{~min}$ [18].

\section{Specific Attenuation Model (SAM) for Rain for Use in Prediction Method}

Electromagnetic waves are absorbed in the atmosphere according to wavelength. Two compounds are responsible for the majority of signal absorption, oxygen $\left(\mathrm{O}_{2}\right)$ and water vapor $\left(\mathrm{H}_{2} \mathrm{O}\right)$. The first peak occurs at $22 \mathrm{GHz}$ due to water vapour, and the second at $63 \mathrm{GHz}$ due to oxygen. The actual amount of water vapour and oxygen in the atmosphere normally declines with an increase in altitude because of the decrease in pressure. Total attenuation through the atmosphere at any frequency, through unobstructed atmosphere, is the sum of free space path loss, attenuation caused by oxygen absorption, and attenuation caused by water vapour absorption. Rain attenuation, when present, adds an additional element [19].

According to ITU-R, India comes under $25 \mathrm{~mm} / \mathrm{hr}$ to $50 \mathrm{~mm} / \mathrm{hr}$ rate of precipitation zone (accurately $42 \mathrm{~mm} / \mathrm{hr}$ ) and is categorized in k-region in global map [20] for a precipitation of $0.01 \%$ of an average year. Normalized total columnar content of cloud liquid water $\left(\mathrm{kg} / \mathrm{m}^{2}\right)$ exceeded for $5 \%$ of year is $1 \mathrm{~kg} / \mathrm{m}^{2}$ [21]. Figure 1 shows the graphical representation of the average rainfall rate of the Almora location for the years 1990-2009; rainfall data has been collected for the 10-year span; average is calculated on the basis of those time spans and hence two curves are used to show the average rainfall rate for the location, which is recorded by meteorological department of India.

ITU-R assembly considers that there is a need to calculate the attenuation due to rain from knowledge of rain rate. Specific attenuation $A(\mathrm{~dB} / \mathrm{Km})$ is derived from the rain rate $R(\mathrm{~mm} / \mathrm{hr})$ using the power law relationship which is a result of an empirical procedure based on the approximate relation between specific attenuation $(A)$ and rain rate $R$. This model is also referred to as the simplified attenuation model (SAM/CCIR) [19].

The coefficients $a$ and $b$ may be determined, as a function of frequency, from the following equations, which have been

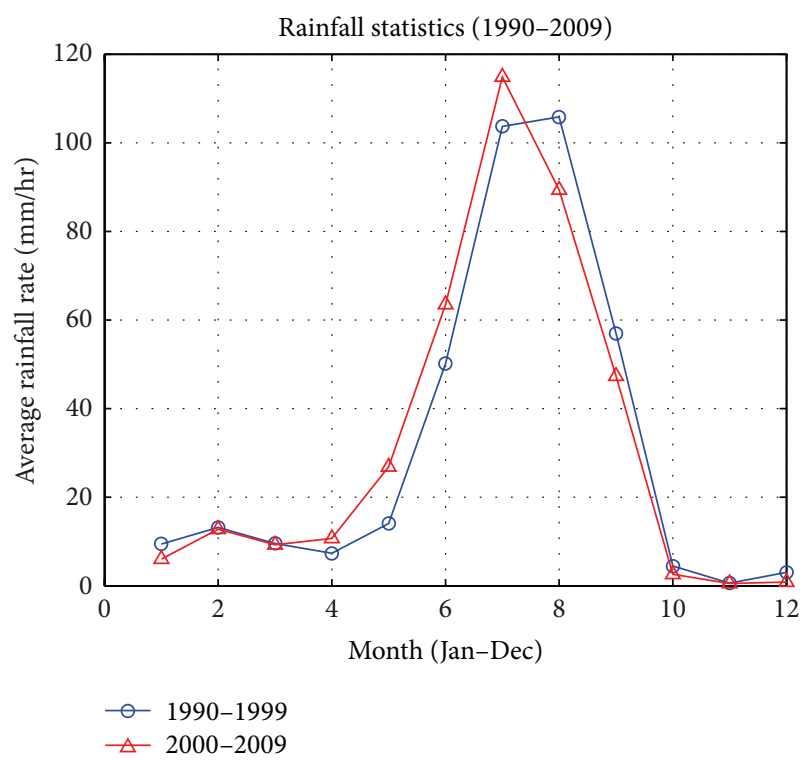

FIGURE 1: Graphical representation of the average rainfall rate of the Almora location for the years 1990-2009.

derived from curve-fitting to power-law coefficients derived from scattering calculations [7]:

$$
\begin{aligned}
\log a & =\sum_{j=1}^{4}\left(x_{j} \exp \left[-\left(\frac{\log f-y_{j}}{z_{j}}\right)^{2}\right]\right)+m_{k} \log f+z_{k} \\
b & =\sum_{i=1}^{5}\left(x_{i} \exp \left[-\left(\frac{\log f-y_{i}}{z_{i}}\right)^{2}\right]\right)+m_{\alpha} \log f+z_{\alpha}
\end{aligned}
$$

where $f$ is frequency $(\mathrm{GHz})$ from 1 to $1000 \mathrm{GHz}, a$ is either $a_{H}$ or $a_{V}, b$ is either $b_{H}$ or $b_{V}$, and $\log x=\log _{10} x$, where $a_{H}, a_{V}, b_{H}, b_{V}$ are coefficients for horizontal polarization $(H)$ and vertical paths for polarization $(V)$.

$R$ is the rain rate in $\mathrm{mm} / \mathrm{hr}$ obtained from metrological data. Parameters $a$ and $b$ are functions of frequency and polarization and are obtained from experimental results. These values are given in tabular form by ITU-R and can be directly accessed from site [22]. The path loss exponent value depends on the obstruction in the radio channel. For free space line-of-sight propagation, the path loss exponent values are two and mathematically expressed as in [22]

$$
\begin{gathered}
a=4.21 \times 10^{-5} f^{2.42} \quad(\text { for } 2.9 \mathrm{GHz} \leq f 54 \mathrm{GHz}) \\
a=4.09 \times 10^{-20} f^{0.069} \quad(\text { for } 54 \mathrm{GHz} \leq f 180 \mathrm{Ghz}) \\
b=1.41 f^{-0.0779} \quad(\text { for } 8.5 \mathrm{Ghz} \leq f \leq 25 \mathrm{Ghz}) \\
b=2063 f^{-0.272} \quad(\text { for } 25 \mathrm{GHz} \leq f \leq 164 \mathrm{GHz}) .
\end{gathered}
$$

Equation (4) can be calculated using (3) or can be directly accessed using the ITU-R recommendation, on the basis of the values available in ITU-R P.838-2 [17] and P.838-3 [7]. 


\section{Result and Declaration}

The results by using the specific attenuation method approach for prediction of rain attenuation on microwave links (frequencies $10 \mathrm{GHz}, 20 \mathrm{GHz}, 30 \mathrm{GHz}$, and $60 \mathrm{GHz}$ ) have been evaluated using the last 20-year rainfall data for Almora, Uttarakhand. Specific attenuation model is one of the ITU$\mathrm{R}$ models and is highly used to predict rain attenuation; attenuation is evaluated with respect to rainfall rate. All the graphs (Figures 1-7) are plotted using MATLAB for the rainfall values taken from Indian Meteorological Department Pune (India) and attenuation values which are calculated with the help of mathematical expression provided in (1) and (4) in this paper.

Figure 2 shows the estimated values of total atmospheric attenuation of region for rainfall rate derived from meteorological site. Rain attenuation is calculated by using (1). It shows that, for the region, the total atmospheric attenuation is very high as the rainfall rate for the location is high. For higher frequencies at higher rainfall rate the total atmospheric attenuation increases constantly and can be very high and it increases constantly whereas rain attenuation after a limit starts to decrease as shown in Figure 3. Rain attenuation affects microwave frequency above $10 \mathrm{GHz}$ as mentioned earlier in this paper and ITU-R models perform very well for low rainfall region; predicted and estimated values results at $10 \mathrm{GHz}$ for the location show small variation in attenuation (Figure 4). At $24 \mathrm{GHz}$ in Figure 7, both predicted and measured values are the same which shows that ITU-R model performs well for the low rainfall rate at low frequencies. Figures 5 and 6 show the actual graphical representation of rainfall rate available from the meteorological department [23] and rain attenuation for the Almora region which are measured by (1). Figure 7 shows the actual variation in the measured and estimated values or predicated values of attenuation which shows that there is a need to develop a regional map for the location and ITU-R predicted values are not quite good enough to predict the attenuation in microwave signals for higher frequencies and for higher rainfall rate. A glance over rain data for Almora reveals that rainfall and rain rate vary considerably from month to month to year to year.

Hence, a regional rain map has to be developed to enable accurate radio link design at millimetric wave lengths, where attenuation due to rain is a major source of propagation outage. Result has been evaluated by using exponential law for the site (Almora, Uttarakhand) with different rainfall rate; the results help find that rain rate and rain precipitation affect attenuation adversely. Attenuation is very high for higher rain rate [24], and ITU-R specific attenuation model when compared with the results shows variation for higher rain rate for Uttarakhand region.

\section{Conclusion}

The result in this paper will be helpful for the purpose of efficient microwave link establishment in location (Uttarakhand) as mentioned in the second section of this paper. The importance of proper knowledge of rain attenuation in the

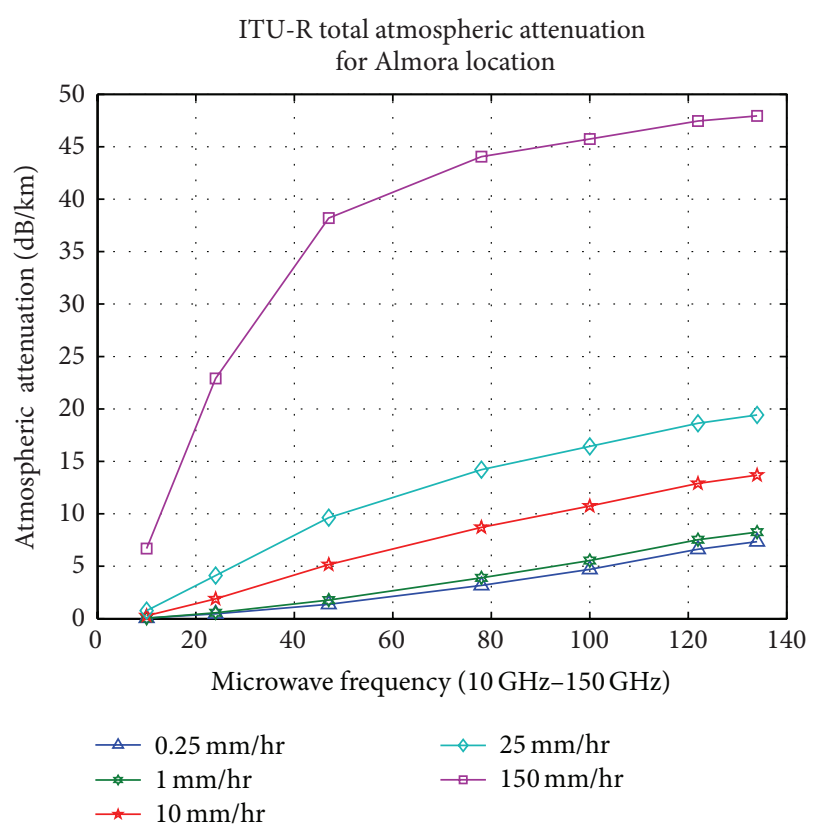

FIGURE 2: Total atmospheric attenuation estimated by ITU-R for Almora region; values are measured by using standard formulas which can be derived from ITU-R directly [7].

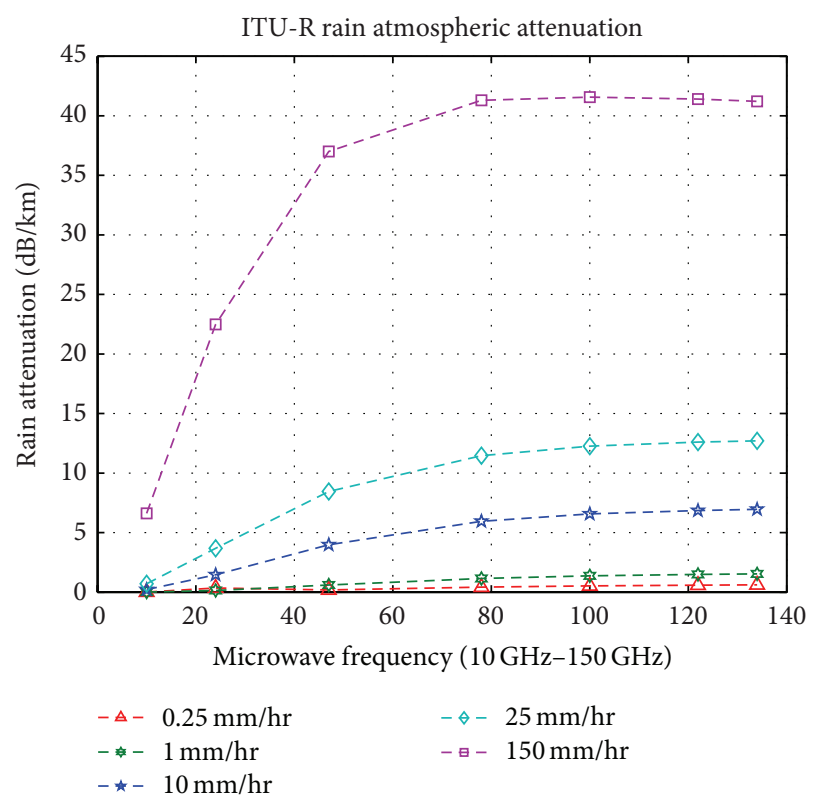

FIgURE 3: Predicted attenuation due to rain for the region, which is measured by using the ITU standards.

designing of a microwave link and with rainfall data which is collected for this experiment other useful lines of research can be made, although the rain attenuation results are calculated with precise methods. However, more tests and analysis need to be done in order to validate the proposed measures, to further understand their physical meaning and existence, and to apply the finding to search for ways of enhancing the system. 


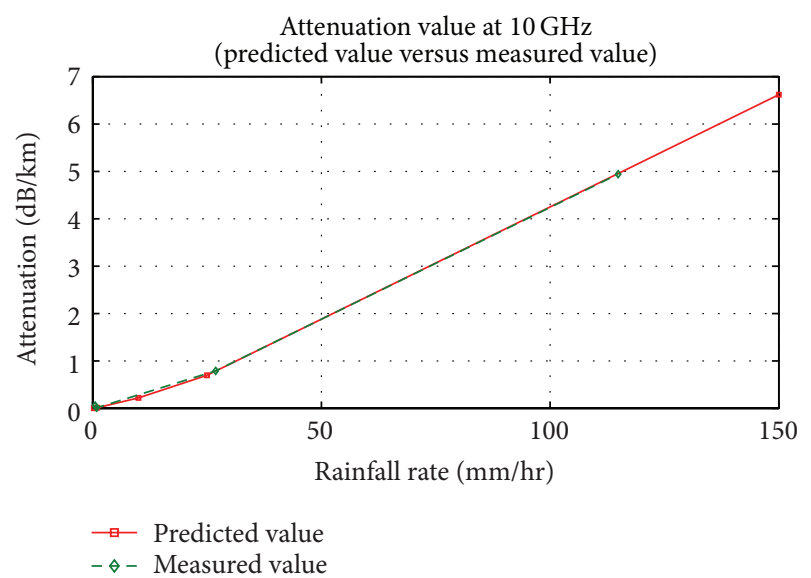

FIGURE 4: Compared attenuation between predicted and measured values at $10 \mathrm{GHz}$.

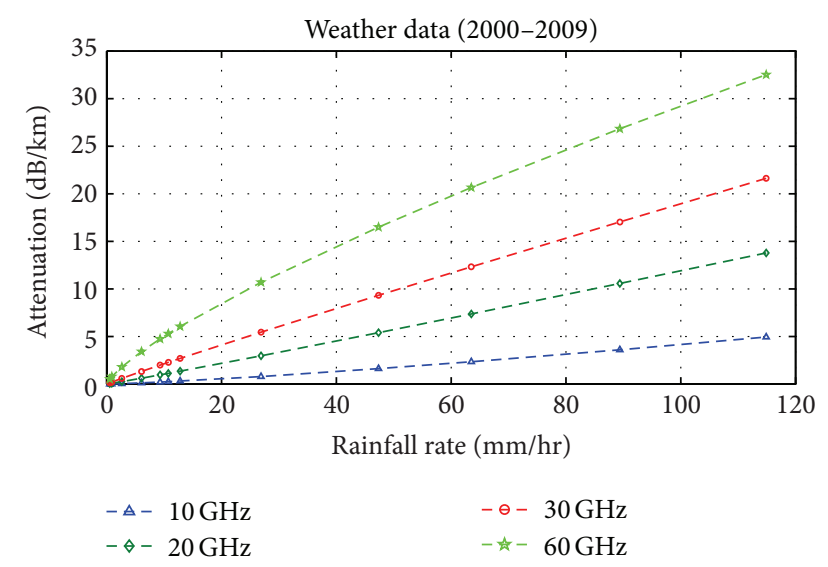

FIGURE 5: Measured values of the rain attenuation of the region (at $10,20,30$, and $60 \mathrm{GHz}$ ) for the years 2000-2009.

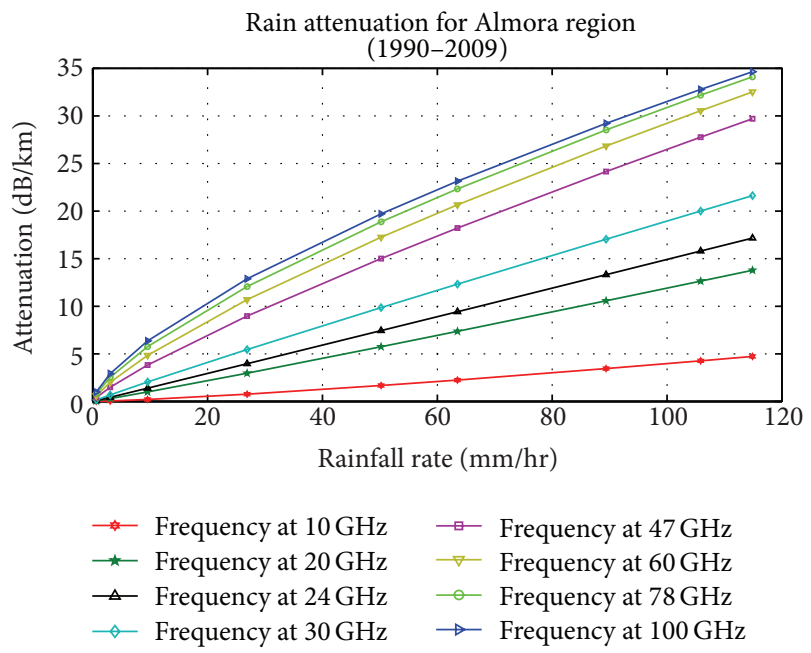

FIGURE 6: Measured values of the rain attenuation of the region (at $10,20,24,47,60,78$, and $100 \mathrm{GHz}$ ) for the years 1990-2009.

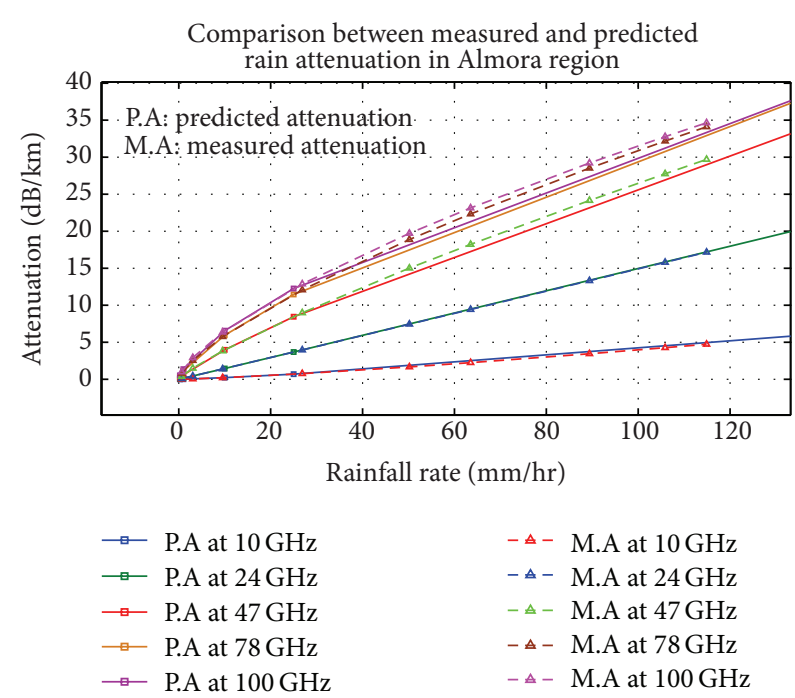

FIGURE 7: Comparison between measured and estimated (predicted) values of rain attenuation in Almora region at microwave frequency for the years 1990-2009.

The current results will serve as a good tool for satellite system designers for improving communication satellite systems in Uttarakhand. On the basis of attenuation the rainfall rate can be achieved. Microwave signals being used for cell towers are monitored routinely. On the basis of database obtained, we can now implement this data to predict rainfall for a given area. The proposed future work in this area may focus on keeping a track on the rainfall status of an area by monitoring the level of attenuation obtained from the database. This database can potentially be counteracted by using received signal level data from the enormous number of microwave links used in commercial cellular communication networks for the Uttarakhand region. This work can be used to monitor the rainfall rate in real time. In those parts of the region where networks of dedicated ground based rainfall sensors are often virtually absent, it would also decrease the cost of establishment of new rain gauge(s) for measuring the rainfall level. This would help the meteorology and remote sensing department as well.

There are many questions still unanswered; hopefully, await for the improvement of the existing instruments, availability of data, techniques, and development of the new ones.

\section{Conflict of Interests}

The authors declare that there is no conflict of interests regarding the publication of this paper.

\section{Acknowledgments}

The authors are extremely thankful to BTKIT, Dwarahat, for funding the project and faculty members for providing all necessary help and guidance; this project is funded by TEQIP-II. Also thanks are due to Indian Meteorological Department for providing valuable rainfall data, to 
Mr. Yusuf A. Abdulrahman for his helpful suggestion in solving the complex problems, and to Mr. Deepak Rawat (PG Scholar, BTKIT, Dwarahat) and Mr. Rohit Joshi (PG Scholar, GEHU, Dehradun) for their valuable support and comments throughout the research work. The authors would like to thank the anonymous reviewers for their valuable comments and suggestion to improve the quality of the paper and all people who directly or indirectly helped in this project.

\section{References}

[1] N. Elfadil, Z. Nadir, M. A. Salam, and J. Rao, "Microwave attenuation studies due to rain for communication links operating in Malaysia," Georgian Electronic Scientific Journal: Computer Science \& Telecommunication, no. 5, 2005.

[2] D. Y. Choi, J. Y. Pyun, S. K. Noh, and S. W. Lee, "Comparision of measured rain attenuation in the $12.25 \mathrm{GHz}$ band with prediction by the ITU-R model," International Journal of Antennas and Propagation, vol. 2012, Article ID 415398, 5 pages, 2012.

[3] T. C. Ramadorai, "Rain attenuation and prediction in the Satellite-Earth Path," in Proceedings of the Workshop on HF VHF and Microwave Communications, New Delhi, India, February 1987.

[4] J. W. F. Goddard, "Propagation in rain and cloud spatial temporal structures of rain," in Propagation of Radio Waves, IEE, London, UK, 2nd edition, 2013.

[5] Y. A. Abdulrahman, R. Islam, and T. A. Rahman, "An improved ITU-R rain attenuation prediction model over terrestrial microwave links in tropical region," EURASIP Journal on Wireless Communications and Networking, vol. 2012, article 189, 2012.

[6] L. A. R. Da Silva Mello, M. S. Pontes, R. M. de Souza, and N. A. Pérez-García, "Prediction of rain attenuation in terrestrial links using full rainfall rate distribution," Electronics Letters, vol. 43, no. 25, pp. 1442-1443, 2007.

[7] "Specific attenuation model for rain for use in prediction methods," ITU-R Rec P. 838-3.

[8] C. F. Bohren and D. R. Huffman, Absorption and Scattering of Light by Small Particles, John Wiley \& Sons, New York, NY, USA, 1983.

[9] D. Colton and R. Kress, Inverse Acoustic and Electromagnetic Scattering Theory, Springer, New York, NY, USA, 1998.

[10] S. Chakraborti, "Verification of the Rayleigh scattering cross section," The American Journal of Physics, vol. 75, no. 9, pp. 824826, 2007.

[11] M. R. Islam and A. R. Tharek, "Propagation study of microwave signals based on rain attenuation data at $26 \mathrm{GHz}$ and $38 \mathrm{GHz}$ measured in Malaysia," IEEE Transactions on Communications, p. 602, 1999.

[12] ITU-R Recommendation, Propagation Data and Prediction Models Required for the Design of Terrestrial Line-of-Sight Systems, ITU-R, Geneva, Switzerland, 2001.

[13] J. S. Ojo, M. O. Ajewole, and S. K. Sarkar, "Rain rate and rain attenuation prediction for satellite communication in $\mathrm{Ku}$ and Ka bands over Nigeria," Progress in Electromagnetic Research B, vol. 5, pp. 207-223, 2008.

[14] R. K. Crane, "Evaluation of global and CCIR models for estimation of rain rate statistics," Radio Science, vol. 20, no. 4 , pp. 865-887, 1985.

[15] COST 255, Final Document: Radio Propagation modeling for new SatCom services in Ku-band and above, 2002.
[16] A. Maitra, "Rain attenuation modeling from measurements of rain drop size distribution in the Indian region," IEEE Antennas and Wireless Propagation Letters, vol. 3, no. 1, pp. 180-181, 2004.

[17] "Specific attenuation model for rain for use in prediction methods," ITU-R Rec P. 838-2.

[18] A. A. Ali, M. A. Alhaider, and M. A. Shatila, "Rain map for radiowave propagation design in Saudi Arabia," International Journal of Infrared and Millimeter Waves, vol. 7, no. 11, pp. 17771793, 1986.

[19] A. Y. Abdulrahman, T. A. Rahman, S. K. A. Rahim, and M. R. Ul Islam, "A new rain attenuation conversion technique for tropical regions," Progress in Electromagnetics Research B, no. 26, pp. 5367, 2010.

[20] ITU-R P. 837-6 Characteristics of Precipitation for propagation Model.

[21] ITU-R P. 836-4 Water vapour: surface density and total columnar content and ITU-R P. 618-10 Propagation data and prediction methods required for the design of Earth-space telecommunication systems.

[22] W. Zhang and N. Moayeri, "Power Law Parameters of Rain Specific Attenuation," National Institutes of standards and Technology, IEEE 802, 16cc-99/24, 1999.

[23] M. J. Rajeevan, J. Bhate, J. D. Kale, and B. Lal, "High resolution daily gridded rainfall data for the Indian region: analysis of break and active monsoon spells," Current Science, vol. 91, no. 3, pp. 296-306, 2006.

[24] U. Siddique, L. Ahmad, and G. Raja, "Microwave attenuation and prediction of rain outage for wireless networks in Pakistan's tropical region," International Journal of Microwave Science and Technology, vol. 2011, Article ID 714927, 6 pages, 2011. 

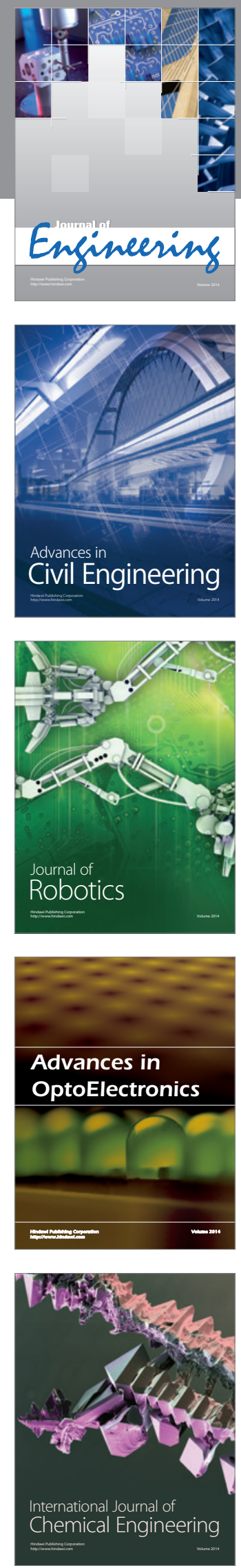

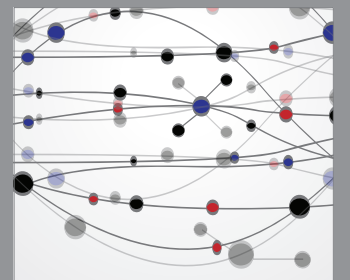

The Scientific World Journal
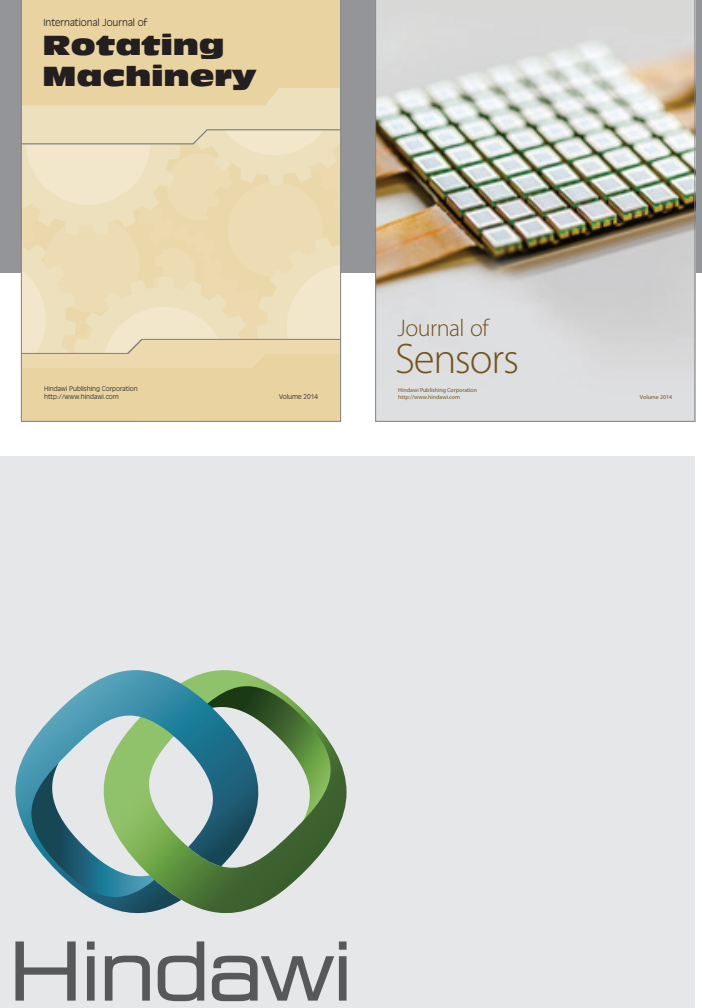

Submit your manuscripts at http://www.hindawi.com
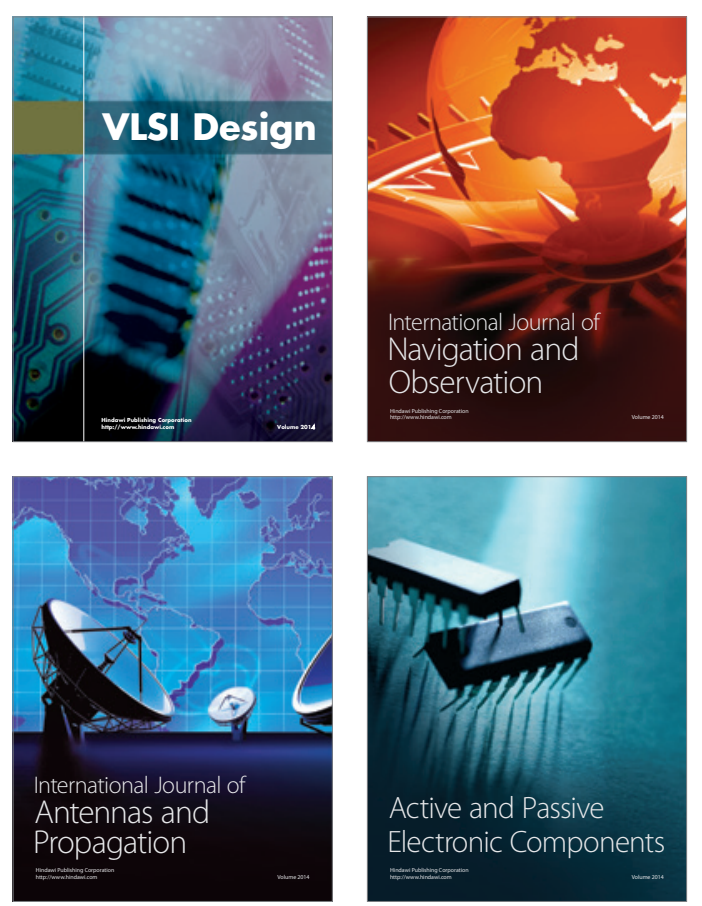
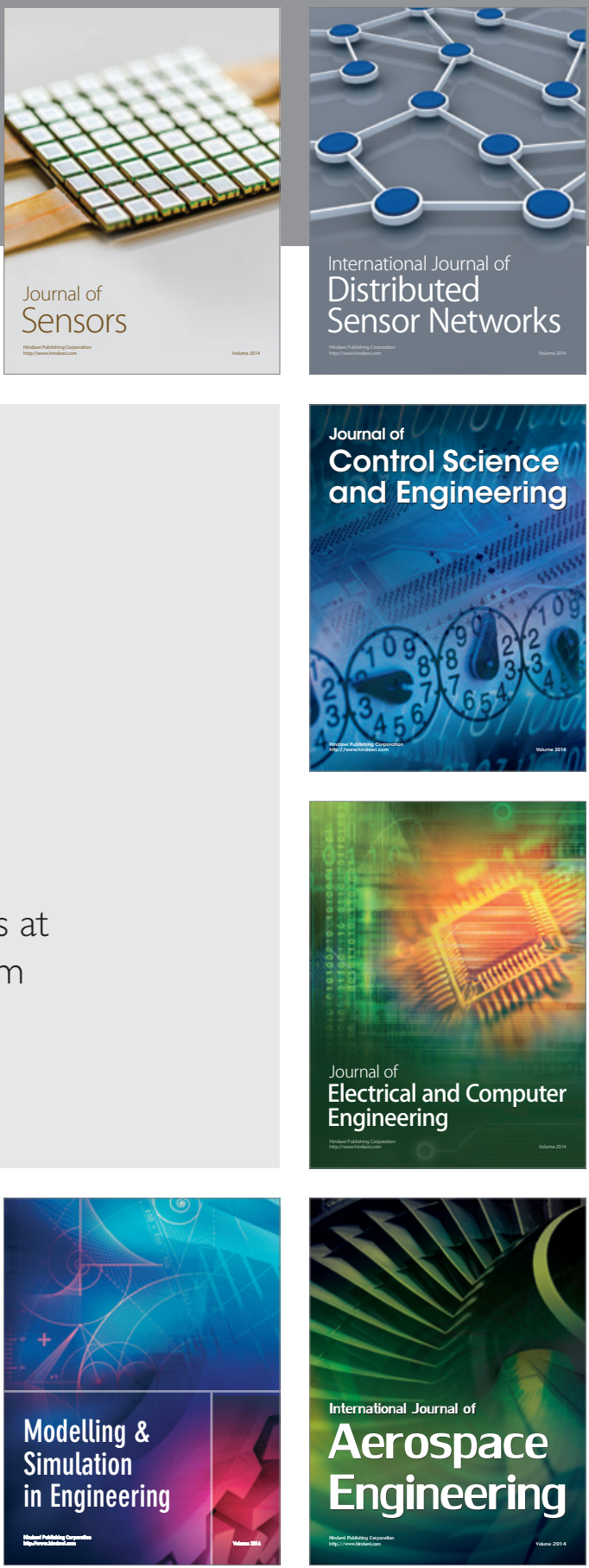

Journal of

Control Science

and Engineering
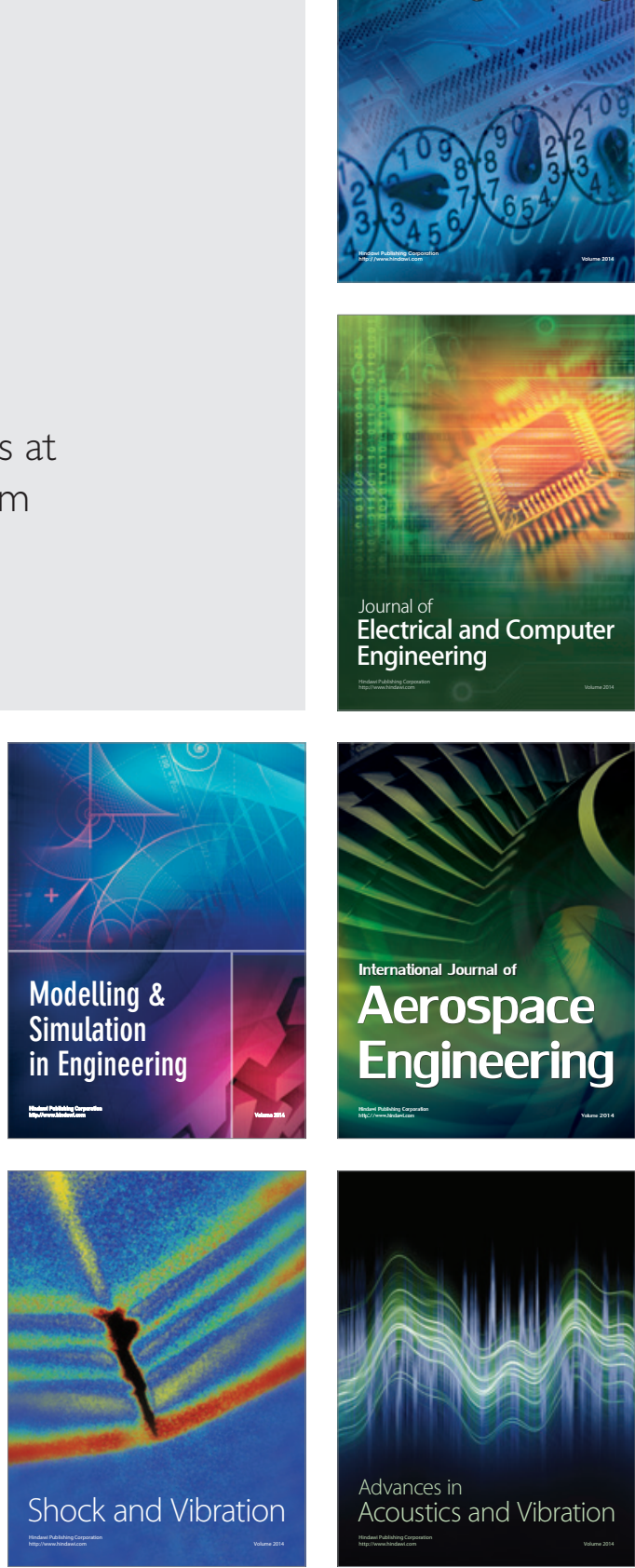